\title{
ОПТИМАЛЬНОСТЬ ПРИНЯТИЯ УПРАВЛЕНЧЕСКОГО РЕШЕНИЯ НА УРОВНЕ ГОСУДАРСТВА В УСЛОВИЯХ РАСПРОСТРАНЕНИЯ КОРОНАВИРУСНОЙ ИНФЕКЦИИ COVID-19: МАТЕМАТИЧЕСКОЕ МОДЕЛИРОВАНИЕ
}

\author{
Кудряшов П.С., \\ Грязнов А.С. \\ Нижегородский институт управления - филиала РАНХиГС \\ г. Нижний Новгород, Россия
}

Данная статья включает анализ расходов ведущих государств мира на борьбу с COVID-19, анализ выдвинутой гипотезы о причине масштабного распространения коронавирусной инфекиии, которая заключается в принятии неправильного управленческого решения, повлиявщего на мировую экономику посредством математического моделирования - теории игр.

Ключевые слова: коронавирус (COVID-19), бюджет страны, закрытие границ государства, теория игр, пандемия.

Эффективность принятия управленческих решений на государственном уровне в условиях пандемии оказывает большое влияние как на социальноэкономическую политику отдельных государств, так и на социальноэкономическую политику в мировом масштабе.

Одно из многочисленных управленческих решений в условиях пандемии - закрытие границ административных единиц государства, являющихся источником распространения инфекции. Иными словами, своевременно принятое решение о закрытии границ в некотором смысле определяет развитие и последствия пандемии.

В конце декабря 2019 года китайские власти сообщили о вспышке пневмонии неизвестного происхождения в городе Ухань. Первые заболевшие имели отношение к рынку морепродуктов. Эксперты предварительно установили, что возбудителем заболевания стал новый тип коронавируса 2019-nCoV[1].

Суды США и Израиля, а также Германии, рассматривают целый ряд коллективных исков, поданных против властей Китая. Заявители считают, что власти Китая так или иначе виновны в распространении коронавируса и требуют взыскать с Пекина триллионы долларов.

"Если бы лидеры Китая не растерялись из-за вспышки и не пытались скрыть распространение заболевания миру, возможно, удалось бы лучше подготовиться к нему", - пишет член Палаты представителей Конгресса США республиканец Джим Бэнкс в письме, адресованном коллегам [4].

Страны пытаются обвинить Китай в распространении коронавируса. Это значит, что Китай будет обязан возместить затраты стран на борьбу с вирусом. 
Если суды подтвердят вину Китая, то тот будет выплачивать странам-истцам триллионы.

Итак, COVID-19 - инфекционное заболевание, вызванное новым видом коронавируса, которым человек предположительно заразился от животных. Точный источник заражения пока не установлен.

Сегодня вирус уже распространился за пределы Китая по всем континентам. Страны с наибольшим количеством случаев заражения: США, Италия, Испания, Германия, Франция и Иран.

Анализ развития коронавирусной инфекции в России на текущий момент позволяет выделить следующую тенденцию - ежедневное увеличение количества заражённых: 10.04. - 1786, 11.04. - 1667, 12.04. - 2186, 13.04.- 2558, 14.04. - 2774, 15.04. - 3388, 16.04. - 3448, 17.04. - 4070, 18.04 - 4785 (график 1). Количество зараженных коронавирусной инфекцией в России на 18 апреля 2020 года составляет 36793 человека, в мире - 2293644 человек. Общее количество стран, пораженных коронавирусной инфекцией, равно 183 [3].

Последствия пандемии, по оценкам экспертов Bloomberg, при самом негативном варианте развития событий обусловлено потерями мировой экономики до \$2,7 трлн[2].

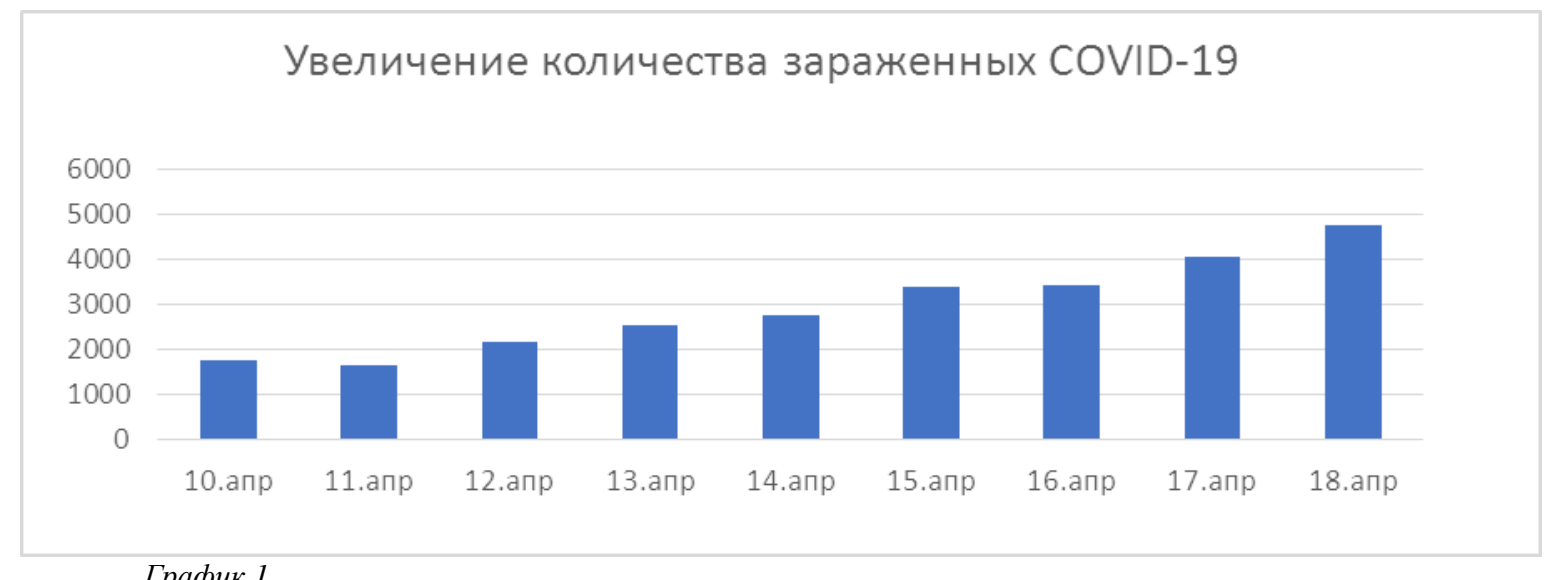

График 1

Все страны, где зарегистрированы случаи заражения коронавирусом, выделяют средства на борьбу с коронавирусом, в том числе на помощь национальным службам здравоохранения, на укрепление системы здравоохранения, индивидуальные денежные выплаты и другое. Размер выделенных денежных средств на перечисленные выше цели в ведущих странах мира составляет [5]:

1. США - $\$ 3,5$ трлн;

2. Германия - $\$ 810$ млрд;

3. Великобритания - $\$ 424$ млрд;

4. Испания - \$220 млрд;

5. Канада - \$107 млрд;

6. Франция - $\$ 50$ млрд;

7. Италия - \$28 млрд;

8. Китай - \$15,93 млрд; 


\section{9. Россия - $\$ 3,8$ млрд;}

10. Украина - $\$ 7$ млн.

Таким образом, на сегодняшний день в общей сумме страны мира в среднем на борьбу с коронавирусом потратили 5 триллионов 158 миллиардов 730 миллионов долларов США.

Предположительно, распространение коронавирусной инфекции по всему миру возможно было бы избежать при соблюдении следующих условий: своевременно закрытые границы; своевременное введение карантина. Для доказательства упомянутой гипотезы, стоит обратиться к такому математическому инструменту как теория игр: теория игр в условиях неопределённости или «игры с природой». Использование данного математического инструмента обусловлено следующими вариантами управленческих решений:

- необходимо закрыть границы Китая - A1;

- оставить границы Китая открытыми - А2.

При этом природа (а в данном случае под природой понимается не зависящий от принятых управленческих решений распространяющийся вирус), способна вести себя следующим образом;

- нераспространение коронавируса за пределы страны - П2;

- единичные случаи заражения в других странах при минимальном риске дальнейшего распространения коронавируса - ПЗ.

На основании выше представленных условий необходимо составить матрицу игры, результатами которой будут затраты на борьбу с коронавирусом в млн. долларов США:

a11 - при закрытых границах Китая в условиях эпидемиологического распространения вируса страны мира тратят денежные средства на борьбу с коронавирусом, и при этом Китай теряет прибыль от внешней торговли;

a12 - при закрытых границах в условиях нераспространения вируса Китай тратит денежные средства на борьбу с коронавирусом и при этом теряет прибыль от внешней торговли;

a13 - при закрытых границах Китая в условиях частичного распространения вируса страны мира тратят денежные средства на борьбу с коронавирусом, и при этом Китай теряет прибыль от внешней торговли;

a21 - при открытых границах Китая в условиях эпидемиологического распространения вируса страны мира тратят денежные средства на борьбу с коронавирусом;

a22 - при открытых границах в условиях нераспространения вируса Китай тратит денежные средства на борьбу с коронавирусом;

a23 - при открытых границах Китая в условиях частичного распространения вируса страны мира тратят денежные средства на борьбу с коронавирусом: 


\begin{tabular}{|l|l|l|l|}
\hline & П1 & П2 & П3 \\
\hline $\mathbf{A 1}$ & 5750,8 & 607,9 & 827 \\
\hline $\mathbf{A 2}$ & 5158,73 & 15,93 & 235 \\
\hline
\end{tabular}

Для решения данной игры воспользуемся следующими критериями: критерием Байеса (КБ), критерием Вальда (КВ), критерием Гурвица (КГ), критерием максимума (КМ). Построим матрицу для расчёта данных критериев:

\begin{tabular}{|c|l|l|l|l|l|l|l|}
\hline & П1 & $\mathbf{\Pi 2}$ & $\mathbf{\Pi 3}$ & КБ & КВ & $\begin{array}{c}\text { КГ } \\
(\lambda=\mathbf{0 , 5})\end{array}$ & КМ \\
\hline $\mathbf{A 1}$ & 5750,8 & 607,9 & 827 & 2371,28 & 5750,8 & 3179,35 & 607,9 \\
\hline $\mathbf{A 2}$ & 5158,73 & 15,93 & 235 & 1785,19 & 5158,73 & 2587,33 & 15,93 \\
\hline Выбор & & & & $\mathbf{A 2}$ & $\mathbf{A 2}$ & $\mathbf{A 2}$ & $\mathbf{A 2}$ \\
\hline
\end{tabular}

Таким образом, согласно теории игр, чтобы понести минимальные потери как Китаю, так и всему миру, нужно придерживаться стратегии А2 - открытие границ.

Рассмотрим игру с теми же условиями, но за результаты новой игры возьмём не затраты на борьбу с коронавирусом, а число жертв (смертей) от коронавируса по всему миру в количестве человек:

a11 - при закрытых границах в условиях эпидемиологического распространения вируса от коронавируса скончалось определённое количество человек в мире;

a12 - при закрытых границах в условиях нераспространения вируса от коронавируса скончалось определённое количество человек в Китае;

a13 - при закрытых границах в условиях частичного распространения вируса от коронавируса скончалось определённое количество человек в мире;

a21 - при открытых границах в условиях эпидемиологического распространения вируса от коронавируса скончалось определённое количество человек в мире;

a22 - при открытых границах в условиях нераспространения вируса от коронавируса скончалось определённое количество человек в Китае;

a23 - при открытых границах в условиях частичного распространения вируса от коронавируса скончалось определённое количество человек в мире:

\begin{tabular}{|l|l|l|l|}
\hline & П1 & $\boldsymbol{\Pi 2}$ & $\boldsymbol{\Pi 3}$ \\
\hline $\mathbf{A 1}$ & 80000 & 4650 & 4800 \\
\hline $\mathbf{A 2}$ & 163200 & 4650 & 5000 \\
\hline
\end{tabular}


Для решения этой игры воспользуемся такими же критериями: критерием Байеса (КБ), Критерием Вальда (КВ), Критерием Гурвица (КГ), Критерием максимума (КМ). Построим матрицу для расчета этих критериев:

\begin{tabular}{|c|c|c|c|c|c|c|c|}
\hline & П1 & П2 & П3 & КБ & КВ & $\begin{array}{c}\text { КГ } \\
(\lambda=\mathbf{0 , 5})\end{array}$ & КМ \\
\hline $\mathbf{A 1}$ & 80000 & 4650 & 4800 & 29518 & 80000 & 42325 & 4650 \\
\hline $\mathbf{A 2}$ & 163200 & 4650 & 5000 & 57040 & 163200 & 83925 & 4650 \\
\hline Выбор & & & & $\mathbf{A 1}$ & $\mathbf{A 1}$ & $\mathbf{A 1}$ & $\mathbf{A 1}=\mathbf{A 2}$ \\
\hline
\end{tabular}

Таким образом, для того, чтобы избежать многочисленных жертв по всему миру, необходимо было закрыть границы Китая. В этом случае жертв (смертей) от коронавируса было бы в 35 меньше. Это значит, что в среднем число умерших от коронавируса в каждой стране равно числу умерших от коронавируса в Китае, где на данный момент пик эпидемии пройден.

Согласно вышеприведенным данным, власти Китая выбрали путь, выгодный экономически, а не демографически (социально). Результат этого свыше 163200 смертей с затратами в 5158,73 млн. долларов США, а не 4700 смертей с затратами в 6000 млн. долларов США.

Таким образом, проведенное исследование даёт основание предполагать, что власти Китая могли принять разумное, экономически выгодное управленческое решение, чего, к сожалению, не произошло. Решение скрыть вспышку коронавируса в стране от мира на тот момент казалось экономически эффективным. Это произошло из-за просчёта и недооценки опасности ситуации.

\section{Список литературы}

1. РосБизнесКонсалтинг||[электронный ресурс]. - URL: https://www.rbc.ru //URL: https://www.rbc.ru/society/16/02/2020/5e48dfa79a79 $4712 \mathrm{e} 68 \mathrm{dc} 1 \mathrm{f} 4$.

2. РосБизнесКонсалтинг||[электронный pecypc]. https://www.rbc.ru //URL:https://www.rbc.ru/economics/07/03/2020/5e6355ac9a7947a8e27817e6.

3. Российская транснациональная компания «Яндекс» ||[электронный pecypc]. - URL: https://yandex.ru/// URL: https://yandex.ru/covid19.

4. Московский комсомолец || [электронный ресурс] https://www.mk.ru // URL: https://www.mk.ru/politics/2020/04/09/kitayu-predyavili-trillionnye-iski-zakoronavirus.html.

5. Официальное периодическое издание [электронный pecypc]https://usa.one/// URL: https://usa-one.turbopages.org/s/usa.one /2020/03/strany-vsego-mira-uzhe-vydelili-123-trln-dollarov-na-borbu-s-epidemiejcovid-19/. 